\title{
Anxiety levels in adolescents who stutter
}

\author{
Gordon W. Blood $^{\text {a,* }}$, Ingrid M. Blood ${ }^{\text {a }}$, Kristy Maloney ${ }^{\mathrm{a}}$, \\ Crystal Meyer ${ }^{\mathrm{a}}$, Constance Dean Qualls ${ }^{\mathrm{b}}$ \\ ${ }^{\text {a }}$ The Pennsylvania State University, PA, United States \\ ${ }^{\mathrm{b}}$ State University of New York, College at Buffalo, United States
}

Received 4 April 2006; received in revised form 26 October 2006; accepted 26 October 2006

\begin{abstract}
High levels of anxiety can negatively affect the lives of children and adolescents. Thirty-six adolescents who stutter and 36 adolescents who do not stutter were administered standardized scales for anxiety and self-esteem. Significant differences were found for the total $T$-scores for Revised Children's Manifest Anxiety Scale for the two groups, although both groups mean T-scores were within normal range. Eighty-three percent of adolescents who stutter and $95 \%$ of adolescents who do not stutter earned scores in the normal range. No significant differences were found on the self-esteem scale, with $86 \%$ of adolescents who stutter and $97 \%$ of adolescents who do not stutter earning scores in the normal/positive range. Adolescents who stutter with co-occurring disorders displayed significantly higher levels of anxiety than adolescents who stutter with no co-occurring disorders. No significant differences were found between groups on ethnicity, socioeconomic class, gender and anxiety levels. A positive, significant correlation between anxiety scores and self-esteem scores was found for both groups.
\end{abstract}

Learning outcomes: Readers will learn about and understand (a) the role of anxiety and selfesteem in stuttering; (b) the methods used to evaluate anxiety and self-esteem in adolescents; and (c) the similarities between adolescents who stutter and adolescents who do not stutter on anxiety and self-esteem scales.

(C) 2006 Elsevier Inc. All rights reserved.

* Corresponding author at: Department of Communication Sciences and Disorders, 110 Moore Building, The Pennsylvania State University, University Park, PA 16802, United States. Tel.: +1 8148653177 ;

fax: +1 8148633759 .

E-mail address: f2x@psu.edu (G.W. Blood).

0021-9924/\$ - see front matter (C) 2006 Elsevier Inc. All rights reserved. doi:10.1016/j.jcomdis.2006.10.005 


\section{Introduction}

Living with a chronic disability can negatively influence an individual's emotional and psychosocial adjustment. Stuttering is an unpredictable disorder (Bloodstein, 1995; Guitar, 2005; Manning, 2001; Shapiro, 1999) with conflicting and variable responses from fluent communication partners and reported negative communication experiences (Bebout \& Bradford, 1992; Ham, 1990; Ruscello, Lass, Schmitt, \& Pannbacker, 1994; Turnbaugh, Guitar, \& Hoffman, 1979; Woods \& Williams, 1971). Data from qualitative studies suggest suffering, helplessness, shame, and stigma may be core experiences for some adults who stutter (Corcoran \& Stewart, 1998; Crichton-Smith, 2002; Klompas \& Ross, 2004). These experiences may make persons who stutter more susceptible to negative emotional responses, poorer self-esteem, and higher anxiety levels (Guitar, 2005; Manning, 2001; Shapiro, 1999; Silverman, 2004; Van Riper, 1982).

\subsection{Anxiety and adults who stutter}

Physiological and emotional anxiety has been reported in persons who stutter (Blomgren, Roy, Callister, \& Merrill, 2005; Blood, Blood, Bennett, Simpson, \& Susman, 1994; Blood, Wertz, Blood, Bennett, \& Simpson, 1997; Caruso, Chodzko-Zajko, Bidinger, \& Sommers, 1994; Craig, 1990; Craig, Hancock, Tran, \& Craig, 2003; DeCarle \& Pato, 1996; Dietrich \& Roaan, 2001; Ezrati-Vinacour \& Levin, 2004; Fitzgerald, Djurdjic, \& Maguin, 1992; Gabel, Colcord, \& Petrosino, 2002; Kraaimaat, Jansseen, \& Brutten, 1988; Kraaimaat, Vanryckeghem, \& Van Dam-Baggen, 2002; Mahr \& Torosian, 1999; Menzies, Onslow, \& Packman, 1999; Messenger, Onslow, Packman, \& Menzies, 2004; Miller \& Watson, 1992; Schneier, Wexler, \& Liebewitz, 1997; Weber \& Smith, 1990). Numerous standardized scales, equipment measuring emotional arousal, heart rate, blood pressure, and skin conductance, personality inventories, subjective ratings, sensitivity, avoidance, stress, and distress scales are used to evaluate both state and trait anxiety in persons who stutter. It has been reported that as high as $44 \%$ of clients seeking treatment for stuttering could be assigned a co-occurring social phobia or social anxiety diagnosis (Stein, Baird, \& Walker, 1996). In both state and trait anxiety, Craig (1990) and Ezrati-Vinacour and Levin (2004) showed that clinical samples of people who stutter (PWS) scored higher than control participants.

Researchers question the results of anxiety studies with PWS due to methodical issues (Craig, 1994; Menzies et al., 1999). A report by Menzies et al. (1999) suggests that the (a) construct of anxiety, (b) number of participants, (c) speaking tasks, (d) trait anxiety measures, and (e) treatment status of the participants could bias finding a relationship between anxiety and stuttering. As early as 1994, Craig suggested that treatment for stuttering could have moderating effects on anxiety levels, measurements, and results. In an attempt to control for this bias Craig et al. (2003) examined trait anxiety in a randomized population sample using a standardized anxiety measure. From a random selection and telephone interview of 4689 households, 87 individuals were identified as PWS. Of this group, 63 completed a trait anxiety measure over the telephone. Results revealed that PWS were shown to have higher chronic anxiety levels than the individuals who did not stutter. Craig et al. also reported that "most of the difference is due to those participants whose 
stuttering was more severe and who seek therapy" (p. 1203). In other words, those seeking treatment had higher severity ratings and tended to have higher levels of anxiety. The authors conclude that fluency disorders, if chronic, are associated with higher levels of trait anxiety.

\subsection{Anxiety in children and adolescents}

High levels of anxiety can negatively affect the lives of children and adolescents. Researchers suggest that the prevalence of anxiety disorders in children and adolescents may be as high as 20\% (Costello \& Angold, 1995; Manassis, Avery, Butalia, \& Mendlowitz, 2004; Velting, Setzer, \& Albano, 2004). Studies suggest that children and youth with anxiety disorders may be at higher risk for educational underachievement, depression, poorer social support networks and increased family conflicts (Ameringen, Mancini, \& Farvolden, 2003; Pine, Cohen, Gurley, Brook, \& Ma, 1998; Velting et al., 2004). Recent reviews on the effectiveness of cognitive-behavioral treatments for anxiety, specific phobias, and school refusal offer empirical data on positive treatment outcomes (Balon, 2004; King, Heyne, \& Ollendick, 2005). Studies have also reported that adolescents with disabilities may be at higher risk for anxiety and anxiety related disorders (Hommel et al., 2003; Jackson, Ciechomski, King, Tonge, \& Heyne, 2002; King et al., 2005; King, Ollendick, Gullone, Cummins, \& Josephs, 1990; Williams et al., 2003).

Anxiety disorders have also been reported as more common in children with communication disorders (Beitchman et al., 2001; Cantwell \& Baker, 1987, 1988). A few studies have reported anxiety in children and youth who stutter. These studies have used anxiety measures as predictors of treatment outcomes or relapse in youth and adolescents who stutter (Blood, 1995; Hancock \& Craig, 1998; Kraaimaat et al., 1988). For example, Hancock and Craig (1998) reported that only pre-treatment \%SS and immediate posttreatment anxiety were significant factors in predicting stuttering frequency 1 year after treatment in 77 children aged 9-14 years. In another study examining treatment outcomes in children and adolescents, Hancock et al. (1998) included a measure of trait anxiety. The authors reported no significant differences between groups on state anxiety scores at the 12-month and 2-6-year follow-ups. They did report a trend for participants to become less anxious after 2-6 years of treatment.

Studies have also addressed the specific role and identification of anxiety in youth and adolescents who stutter. Craig and Hancock (1996) in a study examining anxiety in children between 8 and 14 years reported that children who stutter were no more anxious than children who do not stutter of the same age. They concluded that anxiety was not higher in children with more severe stuttering. Beitchman et al. (2001) reported on children with speech and language disorders, including stuttering in children. They employed a longitudinal design in which participants, identified with speech and language disorders at 5 years, were administered psychiatric interviews 14 years later (age 19) to determine the relationship between speech, language impairments and anxiety in young adulthood. Results showed that children with language impairments were significantly more likely to develop anxiety disorders. As mentioned above, the study also examined children with speech disorders including voice, stuttering and dysarthria. The inclusion criterion was very broad. For example, evidence of stuttering was assessed by a master's level 
speech-language pathologist (SLP) based on "the analysis of spontaneous speech, and number, letter and word repetition" (p. 78). The authors of this study did not provide any other information about stuttering behaviors, severity, duration, physical concomitants, standardized/commercially available measures, or attitude assessments, even though the initial assessments were conducted on 5-year-old children. The study included 38 participants grouped as speech impaired category including stuttering, voice and dysarthria for the analyses. Beitchman et al. concluded the speech impaired group did not have significantly different rates of psychiatric outcomes/disorders (including anxiety) from the control group. The results did not provide the number of participants with voice, stuttering or dysarthria disorders, an analysis by speech disorder, or a follow-up determination of the existence of the stuttering, voice or dysarthria speech problems at age 19. The results need to be replicated.

In a follow-up to this study, Voci, Beitchman, Brownlie, and Wilson (2006) used the same methodology to examine social anxiety and the fear of social communication. They posited that early childhood language impairment was a precursor for late adolescent social phobia. Their results showed that individuals with "a history of early language impairment had 2.7 times the odds of having a social phobia by age 19" (p. 1). They also suggested that although the rate of social phobia at age 19 for the 38 participants with early speech impairment (including PWS) was not statistically different from the controls, future research should address the possibility of increased risk in speech impaired participants. The authors do add the disclaimer and limitation that they were "unable to conduct analyses to determine whether language impairment continued to predict social phobia after controlling for other early childhood risk factors" (p. 13).

Blood, Blood, Tellis, and Gabel (2003) summarized studies suggesting that adolescents with physical or psychosocial problems or disabilities are confronted by or experience negative stereotypes from their peers and other individuals which may increase anxiety levels and/or disorders. Although they reported that stuttering did not present a stigmatizing condition for $65 \%$ of adolescents who stutter, $60 \%$ of the participants responded that they "never or rarely" talked about their stuttering. This lack of communication and/or the potential for misinformation about a chronic disability like stuttering could contribute to negative emotional responses and heightened levels of anxiety.

\subsection{Current study}

We decided to study systematically anxiety in adolescents who stutter to increase our understanding of the role of anxiety in stuttering across the lifespan. These findings may assist clinicians and researchers in identifying heightened levels of anxiety as a cooccurring condition in some adolescents who stutter and help in treatment planning and techniques in schools and clinics. This study may also provide additional support for conflicting research reporting anxiety and negative emotional responses across the lifespan of PWS. Menzies et al. (1999) suggested that some of the conflicts reported in the literature about stuttering and anxiety may be related to the measures employed, definitions used, and participants involved in the research. Examining adolescents who stutter may provide information about the development or progression of anxiety in PWS. Few studies have examined anxiety in adolescents. 
Specifically, we wanted to (a) determine overall anxiety indices in adolescents who stutter using a standardized measure; (b) determine overall self-esteem in adolescents who stutter using a standardized measure; (c) examine the relationship between self-esteem and anxiety in adolescents who stutter; and (d) examine the relationship among anxiety and gender, ethnicity, stuttering severity, socioeconomic class, and co-occurring disorders in adolescents who stutter.

\section{Method}

\subsection{Participants}

Participants were 36 students who stutter in the seventh through 12th grade attending suburban, urban and rural schools. Although Craig et al. (2003) suggested that a randomized population sample of PWS have lower levels of anxiety than a clinical sample receiving and/or seeking treatment, we decided to include only adolescents who stutter who were reported to have had treatment. This decision was made for two reasons: one, the convenience of the sample and two, a large percentage of adolescents who stutter attending schools in the United States are diagnosed and exposed to some treatment for a period of time. This might allow us to generalize our findings to students who were currently in treatment in schools.

The sample consisted of $30(83 \%)$ males and $6(17 \%)$ females. The racial/ethnic distribution of the participants was 27 (75\%) white, non-Hispanic, 4 (11\%) AfricanAmerican, and 5 (14\%) Hispanic-American adolescents. Students ranged in age from 12 years 8 months to 18 years 7 months with a mean age of 14.3 years $($ S.D. $=2.7)$. The mean onset of stuttering was reported to be 3.1 years of age (S.D. $=1.3)$. All participants had been enrolled in treatment for their stuttering, with a mean of 11.8 years and a range of $7-$ 14 years. Twenty-nine $(81 \%)$ of the adolescents who stutter were currently enrolled in treatment, while seven $(19 \%)$ had been in treatment for at least 5 years but not within the past 6 months.

For adolescents who stutter, the Stuttering Severity Instrument-3 (Riley, 1994) was used to determine the severity of the stuttering. Only students in the mild, moderate, severe and very severe categories were included. Eight (22.2\%) of the students' stuttering was rated in the mild category, $10(27.7 \%)$ of the students' stuttering was rated in the moderate category, $8(22.2 \%)$ of the students' stuttering was rated in the severe category, while $10(27.7 \%)$ students' stuttering was rated in the very severe category.

Information on socioeconomic status (SES) of all the participants was measured using the Hollingshead Index of Social Position (Hollingshead, 1975; Hollingshead \& Redlich, 1958). The Hollingshead Index is one of the most widely used measures of socioeconomic status in the social science literature and allows for calculation of socioeconomic status scores for both one- and two-parent families. The Index has been shown to be highly correlated with an occupation index designed by the National Opinion Research Center $(r=.92)$ and is used frequently in studies of developmental neuropsychology (Reader, Harris, Schuerholz, \& Denckla, 1994). The Index has been updated to include mother's education and occupation. A value is now assigned to the occupation and education of both 
parents. The mean occupation rating is weighted by multiplying by 5 . The mean education rating is multiplied by 3 . This Index makes use of parents' occupational and educational levels. The theoretical range of scores on the Index is from 1 (highest SES) to 5 (lowest SES). The actual range was 1-5 with a mean SES score of 2.3 (S.D. = 1.2), suggesting middle- to high-class participants. Scores were used to categorize socioeconomic status into high and low classifications with 2.5 as the cutoff between the two groups.

Control subjects were recruited from local school districts and were matched with participants who stuttered from the same grade, ethnicity, gender, and approximate age. Students were excluded if they had been or were currently in speech therapy or had IEP's for treatment services in the schools. SLPs provided information about the treatment status and assurances that participants in the control group did not exhibit fluency disorders. Students currently receiving services as outlined in an IEP and/or medication for anxiety or anxiety related disorders based on self-report were excluded from testing. Parental consent forms and participant assent forms were completed prior to the beginning of the study.

\subsection{Measures}

\subsubsection{Revised Children's Manifest Anxiety Scale}

Each student was administered the Revised Children's Manifest Anxiety Scale (RCMAS) (Reynolds \& Richmond, 2002). The RCMAS is one of the mostly widely used self-report measures for clinical and research purposes in the world (Seligman, Ollendick, Langley, \& Balducci, 2004; White \& Farrell, 2001). The RCMAS is a 37-item, self-report questionnaire that assesses the level and nature of anxiety in children between 6 and 19 years of age. It is also subtitled the "What I Think and Feel" test. It uses a yes/no format to statements classified into one of the three subscales: Physiological Anxiety, Worry/ Oversensitivity and Social Concerns/Concentration. The RCMAS also provides a Lie subscale that acts as a validity scale. Five scores are obtained including: a total anxiety score (mean $=$ a $T$-score of 50 with a standard deviation of \pm 10 points) and four subscales including Physiological Anxiety, Worry/Oversensitivity, Social Concerns/Concentration and Lie subscales. The mean for the subscales $=\mathrm{a} T$-score of 10 with a standard deviation of \pm 3 points. Total anxiety scores range from 0 to 28 which are then converted to $T$-scores for interpretation. The test has been standardized and normed on 4972 students. The Manual describes the interpretation of scale scores in detail and provides extensive normative data for age, gender, and ethnic backgrounds of students.

High scores on the Physiological Anxiety subscale suggest that students may display or manifest certain physiological responses to anxiety. Item content for the Physiological Anxiety subscale includes 10 items such as: "Often I have trouble getting my breath; My hands feel sweaty; I wake up scared some of the time; and Often I feel sick in my stomach." High scores on the Worry/Oversensitivity subscale suggest that students may be nervous or internalize much of the anxiety they are experiencing. The Worry/Oversensitivity subscale contains 11 items such as: "I worry a lot of the time; My feelings get hurt easily; I often worry about something bad happening to me; and I am nervous." High scores on the Social Concerns/Concentration subscale suggest students may not think/feel they are living up to expectations of significant others in their environment. This subscale consists of seven items including: "I feel alone even when people are with me; A lot of people are against 
me; and Others seem to do things easier than I can." The final subscale, labeled the Lie subscale, contains nine items including "I am always kind; I am always good; I never lie; and I never get angry." The Lie subscale is a validity scale with higher scores indicative of inaccurate self-report and a need to please the examiner during the testing by responding in a manner they think the examiner wants them to respond. The authors of the test suggest that participants with high Lie subscale scores should be readministered the test. High scores on the Lie subscale suggest the students have a high need for social acceptance and may have feelings of social isolation or rejection.

\subsubsection{Rosenberg Self-Esteem Scale (RSES)}

Similar to an earlier study (Blood et al., 2003), we also administered the Rosenberg SelfEsteem Scale (RSES) (Rosenberg, 1965). As discussed in that study, the RSES is one of the most widely used scales for measuring self-esteem in the literature (Hagborg, 1996; Rosenberg, 1986). Scores on the RSES are the summed rating of the 10 items concerning feelings of self-worth. Five of the items are positively worded (for example, I feel I have a number of good qualities) and five are negatively worded and reversed scored (for example, I feel I do not have much to be proud of). Ratings are on a 4-point scale from strongly agree to strongly disagree. Lower scores indicate higher self-esteem. Convergent validity of the scale has been demonstrated as the scale correlates significantly with other measures of self-esteem (Rosenberg, 1979). Researchers have demonstrated significant positive relationships between self-esteem and other measures of self-concept and self-regard for school-aged children and adolescents (Hagborg, 1996; Hoge \& McCarthy, 1983; Lorr \& Wunderlich, 1986).

\subsection{Procedures}

Participants were recruited by contacting SLPs in the public schools of Pennsylvania. Letters were mailed to SLPs and/or supervisors in school systems requesting participation in a study examining the anxiety, self-esteem, and communication attitudes of adolescents who stutter. Interested SLPs were directed to complete and return a mailed form identifying potential participants. Follow-up telephone contacts confirmed whether students met the selection criteria. No students repeated a grade level and no students were placed in a special classroom. Information about the study was sent to SLPs with consent and assent forms for parents and participants. Individual testing times were set up for all participants. All adolescents who stuttered were assessed with the Assessment for Fluency Disorders (Blood, 1998). This consisted of a detailed diagnostic interview, including: the reason for referral, definition and present complaint, client's perception of the problem, information about onset, development and progression of the disorder, medical, social, educational and vocational history. Two hundred word spontaneous speech samples and 200 word reading samples were obtained and both molar and molecular analyses were conducted for disfluency type, frequency and duration. In addition, the Stuttering Severity Instrument-3 (Riley, 1994) was used to determine the severity of the stuttering. We also conducted a detailed attitudinal and belief assessment using standardized measures outlined in Blood (1998).

We obtained information about co-occurring disorders from an interview format which was verified by the IEP and SLP's report. Information on the number of co-occurring 
disorders for each participant and type of disorder was used to categorize responses into two groups. Group 1 comprised students with no co-occurring disorders while Group 2 comprised students with co-occurring speech-language disorders (articulation, phonology, expressive language, receptive language and SLI), and non-speech-language disorders (central auditory processing, attention deficits, behavioral disorders, reading problems, neurological disorders). Twenty students (55.5\%) had no co-occurring disorders, while 16 $(44.4 \%)$ reported co-occurring disorders. Finally, information to complete the Hollingshead Index for socioeconomic status (SES) of the students was obtained from parental reports.

\subsection{Data analysis}

Descriptive statistics were computed (means, standard deviations) for the RCMAS, the four Subscale $T$-scores of the RCMAS and the RSES summed scores for all participants. $T$ tests were performed to determine differences between the group membership (stuttering, control); gender (male, female); and socioeconomic status (high and low). Multivariate analysis of variance (MANOVA) were conducted with the total RCMAS $T$-scores, the four Subscale $T$-scores of the RCMAS and RSES summed scores as dependent variables to determine the main effects and interactions for group membership, gender, ethnicity (white, African-American, Hispanic-American), and socioeconomic status. Follow-up univariate analyses of effects were also computed.

$T$-tests were also conducted for the adolescents who stutter for the anxiety and selfesteem measures using co-occurring disorders (presence or absence) as a subgrouping measure. Pearson product moment correlations were computed to determine the relationship between the anxiety and self-esteem scales for both the stuttering and control groups. Correlations were also computed to determine the relationship between the anxiety and self-esteem measures and the raw scores calculated for stuttering severity from the SSI-3.

\section{Results}

\subsection{Descriptive data analyses}

\subsubsection{Anxiety scores}

To determine overall anxiety indices in adolescents who stutter and adolescents who do not stutter, raw scores for the RCMAS were converted to $T$-scores for analyses and ranged from 44 to 81 . Fig. 1 displays the mean scores for all participants for the RCMAS anxiety total score and the four subscale scores. The group mean $T$-score for adolescents who stutter was 57.3 (S.D. 7.3) and 51.7 (S.D. 5.4) for adolescents who do not stutter. Mean $T$ scores on the Physiological Anxiety, Worry/Oversensitivity and Social Concerns/ Concentration and Lie subscales for adolescents who stutter were 10.2 (S.D. 2.3), 10.1 (2.9 S.D.), 9.9 (2.8 S.D.) and 10.2 (2.9 S.D.), respectively. Similarly, mean $T$-scores on the Physiological Anxiety, Worry/Oversensitivity, Social Concerns/Concentration and Lie subscales for adolescents who do not stutter were 9.6 (S.D. 1.9), 9.7 (2.8 S.D.), 9.4 (2.8 


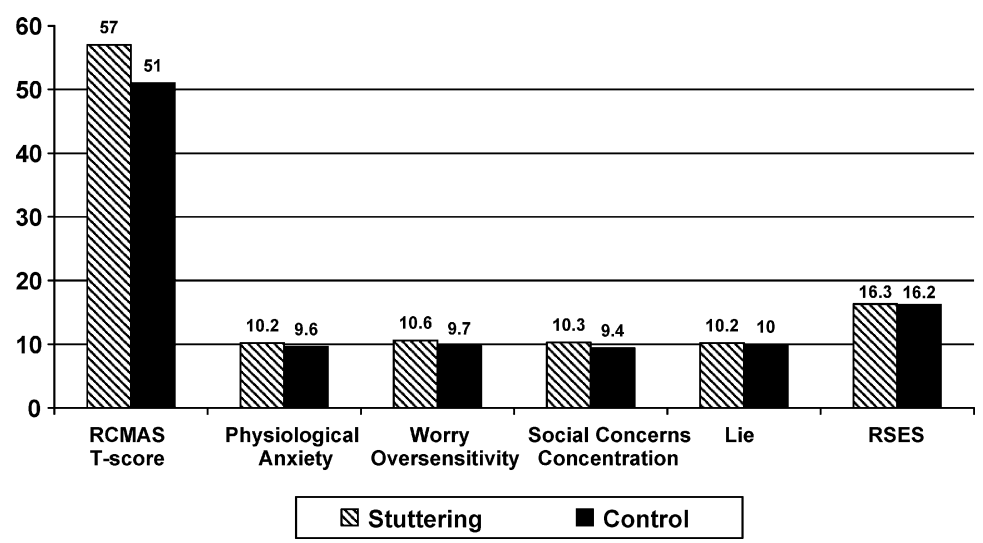

Fig. 1. Mean total T-scores and subscale scores for the Revised Children's Manifest Anxiety Scale for adolescents who stutter and adolescents who do not stutter.

S.D.), and 10.0 (2.9 S.D.), respectively. These scores were very similar to those reported in the RCMAS manual and the standardization data provided where 10 is a normative $T$-score.

Thirty $(83 \%)$ adolescents who stutter and $35(97 \%)$ adolescents who do not stutter scored within one standard deviation of the normative data suggesting that the majority of adolescents who stutter and adolescents who do not stutter report no significant anxiety levels. Fig. 2 plots the RCMAS $T$-scores against the RSES summed scores for adolescents who stutter, while Fig. 3 plots the RCMAS T-scores against the RSES summed scores for adolescents who do not stutter. Although it is obvious that both groups' scores tend to hover around the mean of $T$-score of 50 and the summed score of 16, participants with higher scores on the RCMAS also showed higher scores on the RSES. It can be seen that six participants from the adolescents who stutter group and one from the control group earned scores $>60$ (the higher end) on the RCMAS. Of the six participants who stutter three $(8.3 \%)$ scored one standard deviation above the mean, two $(5.5 \%)$ scored two standard

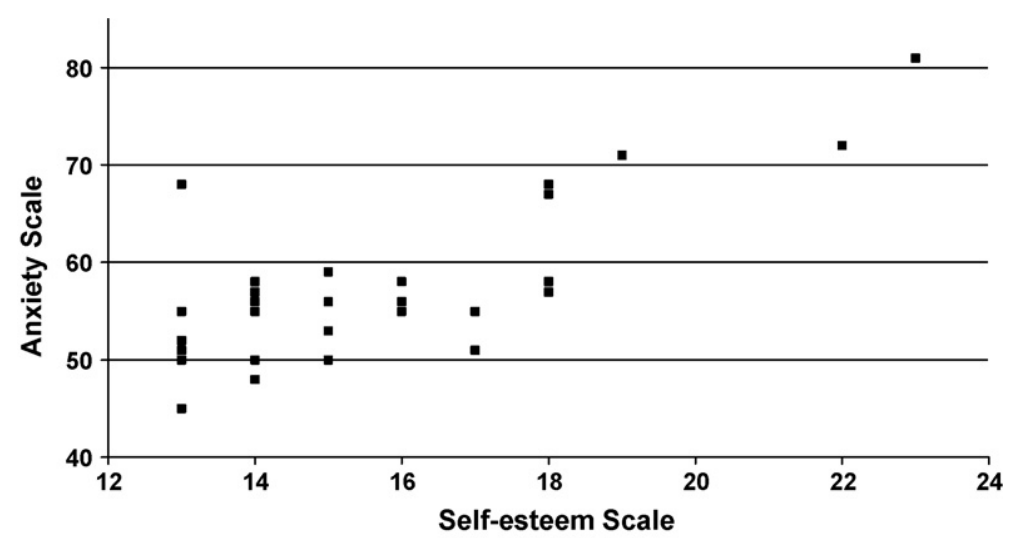

Fig. 2. Scatterplot showing the distribution of scores for the Revised Children's Manifest Anxiety Scale and the self-esteem scale for adolescents who stutter. 


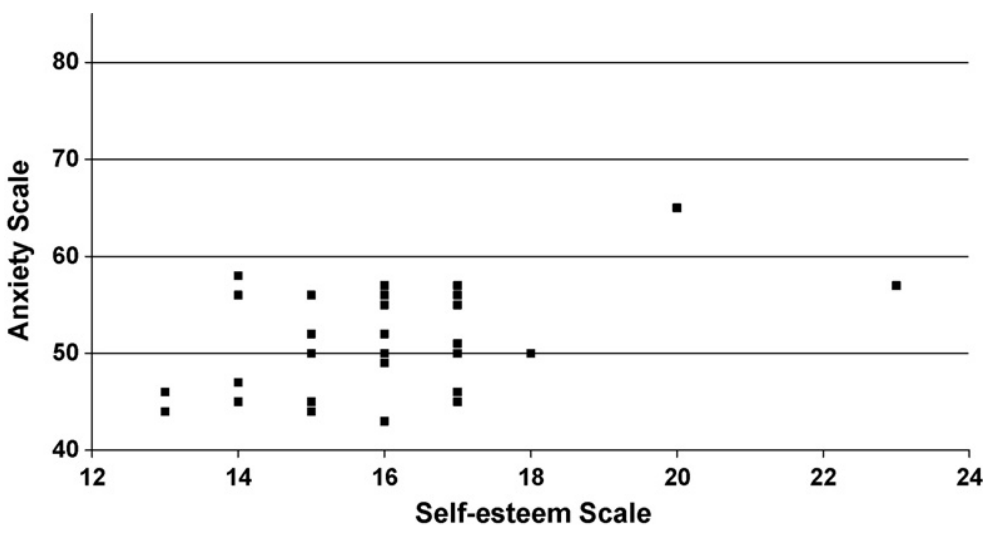

Fig. 3. Scatterplot showing the distribution of scores for the Revised Children's Manifest Anxiety Scale and the self-esteem scale for adolescents who do not stutter.

deviations above the mean, and one (2.7\%) scored three standard deviations above the mean. In contrast, only one participant who did not stutter scored one standard deviation above the mean. This suggests both control and experimental participants earned scores very similar to normative data supplied with the RCMAS on nearly 4972 students.

\subsubsection{Self-esteem scores}

To determine overall self-esteem in adolescents who stutter and adolescents who do not stutter, results of the Rosenberg Self-Esteem Scale (RSES) were computed. Scores ranged from 11 to 23. The group mean score for adolescents who stutter was 16.3 (S.D. 2.6) and 16.2 (S.D. 2.1) for adolescents who do not stutter. Based on the normative data for adolescents, $31(86 \%)$ participants who stutter and $35(97 \%)$ participants who do not stutter scored within one standard deviation suggesting positive to normal self-esteem.

\subsection{Statistical analyses}

\subsubsection{Between group comparisons}

The means and standard deviations of the RCMAS $T$-scores for the two groups are presented in Table 1. Adolescents who stutter presented a significantly higher $T$-score mean on the RCMAS than the controls $t(70)=3.67, p<.001$, Cohen's $d=.86$. Adolescents who stutter reported significantly higher levels of anxiety than their more fluent counterparts. However, it should be noted that both groups of participants earned scores within the normative range (within one standard deviation). The adolescents who stutter scored on the higher end of the normative range. No significant differences between the adolescents who stutter and adolescents who do not stutter were found on the RSES self-esteem scale $t(70)=.15, p=.88$. There were also no other significant differences on the RCMAS $T$ scores, the four subscale scores and the RSES for gender (male and female groups), socioeconomic status (SES) (high and low) or ethnicity (white, African-American and Hispanic-American). To examine the main effects of group, gender, socioeconomic status 
Table 1

RCMAS $T$-score means, standard deviations, $t$-values and effect sizes for all participants

\begin{tabular}{|c|c|c|c|c|c|}
\hline \multirow[t]{2}{*}{ Variable } & \multirow[t]{2}{*}{$N$} & \multirow[t]{2}{*}{ Mean } & \multicolumn{3}{|l|}{ RCMAS $T$-scores } \\
\hline & & & Standard deviation & Significant $p$-value & Effect size \\
\hline \multicolumn{6}{|l|}{ Group } \\
\hline Adolescents who stutter & 36 & 57.3 & 7.3 & $p<.001$ & .86 \\
\hline Adolescents who do not stutter & 36 & 51.7 & 5.4 & & \\
\hline \multicolumn{6}{|l|}{ Gender } \\
\hline Males & 66 & 53.9 & 7.6 & .447 & ns \\
\hline Females & 6 & 52.9 & 7.2 & & \\
\hline \multicolumn{6}{|l|}{ SES level } \\
\hline Low & 23 & 54.9 & 7.2 & .298 & ns \\
\hline High & 49 & 53.6 & 5.9 & & \\
\hline \multicolumn{6}{|c|}{ Co-occurring disorders (only adolescents who stutter) } \\
\hline No co-occurring disorders & 20 & 53.4 & 3.4 & $p<.001$ & 1.4 \\
\hline Co-occurring disorders present & 16 & 62.1 & 8.1 & & \\
\hline
\end{tabular}

(SES), and ethnicity and their possible interactions, a multivariate analysis of variance (MANOVA) was conducted with total RCMAS $T$-scores, the four Subscale $T$-scores and RSES summed scores as dependent variables. The analysis yielded a significant main effect for stuttering and control groups, Wilks' lambda $=.621, F(6,58)=6.03, p<.0000$, $\eta^{2}=.38$, with group membership accounting for $38 \%$ of the variance (1-Wilks' lambda) showing a medium effect size (Cohen, 1988). Follow-up univariate analyses of the main effect for group membership showed that adolescents who stutter reported higher anxiety scores, $F(1,71)=13.7, p<.0000, \eta^{2}=.22$ than did the control group. The RSES scores between the two groups were not significant $\left(F(1,71)=1.02, p=.08, \eta^{2}=.06\right)$. No other significant main effects for the four subscale scores or their interactions were found.

\subsection{Adolescents who stutter}

$T$-tests were computed between adolescents who stutter with no co-occurring disorders and adolescents who stutter with co-occurring disorders. Adolescents who stutter presented a significantly higher $T$-score on the RCMAS (mean $=62.1$; standard deviation $=8.1$ ) than the adolescents who did not display co-occurring disorders (mean $=53.4$; S.D. $=3.4$ ), $t(34)=3.67, p<.000$, Cohen's $d=1.4$.

To examine the relationships between severity of stuttering and the RCMAS $T$-scores, the four subscale scores and the RSES summed scores, a series of Pearson product moment correlations were computed with the raw scores from the SSI-3 Stuttering Severity Instrument. Results revealed no significant correlations for any of the measures with stuttering severity scores.

\subsubsection{Relationships between the anxiety test scores and self-esteem scores}

Significant, positive correlations were found between the RCMAS $T$-score and the RSES summed score for adolescents who stutter and adolescents who do not 
stutter $(r=.75, p<.000 ; r=.49, p<.002$, respectively). Figs. 2 and 3 display the distribution of scores for both groups of participants. If a participant scored within the normative range on the self-esteem scale, she/he was more likely to score within the normative range for anxiety measure. If a student displayed higher anxiety levels on the RCMAS, they were more likely to display poorer/lower self-esteem on the RSES.

\section{Discussion}

Studies support the notion that children and adolescents who stutter are stereotyped as more anxious, stressed or nervous than their more fluent counterparts (Crowe \& Walton, 1981; Ham, 1990; Ruscello et al., 1994; Turnbaugh et al., 1979; Woods \& Williams, 1971). The current findings make an important contribution about anxiety and stuttering in adolescents, especially given the limited number of studies published. Although a small minority of adolescents who stutter scored more than one standard deviation from the mean, $83 \%$ scored within the mean, suggesting typical levels of anxiety as reported for this paper and pencil measure. These data should be useful for adolescents who stutter, their parents, significant key others in their environment (teachers, caregivers, employers), and SLPs working with students who stutter. The data should also help to combat the negative stereotype and potential stigma attached to stuttering in adolescents who stutter. Although the scores of participants who stutter are significantly higher than those of control participants, the range of the scores are still within "normal limits". It should be noted that participants who stutter and displayed co-occurring speech, language and/or non-speech language disorders were more likely to report higher levels of anxiety more than one standard deviation from the mean. All 6 of the 36 participants in this study who scored more than one standard deviation above the mean also had cooccurring disorders. These data support the critical need for interdisciplinary and transdisciplinary teams working with some adolescents who stutter. These students may need to have SLPs, reading specialists, school psychologists and other educational personnel assist in dealing with problems associated with anxiety, stuttering, and cooccurring disorders.

It is possible that we overestimated the number and percentage of adolescents who stutter with high anxiety levels because all of these participants had been or were currently enrolled in treatment. According to Craig et al. (2003), the data of participants enrolled in treatment may bias the results. Craig et al. suggested that PWS with higher anxiety levels are those who seek treatment and display high levels of stuttering severity. The current study included 36 participants who were in treatment and 18 of the 30 were classified as displaying severe or very severe stuttering. This may have confounded the data. Another possible explanation is that individuals who seek treatment and benefit from non-avoidance therapies including desensitization, relaxation, confrontation, instruction in coping strategies, etc., may actually decrease their anxiety levels with regard to stuttering. In this situation we may have underestimated the number and percentage of adolescents who stutter with heightened anxiety levels. Future research would need to explore the specific effects of treatment in PWS. 
The results of this study support earlier research concerning the general positive selfesteem of adolescents who stutter (Blood et al., 2003; Yovetich, Leschied, \& Flicht, 2000). Our results suggest that adolescents who stutter have normal self-esteem, similar to that of their more fluent counterparts. The results also show a strong positive relationship between self-esteem and levels of anxiety for both groups. Other studies have reported positive relationships between self-esteem and anxiety in adolescents and adults (Bandura, Pastorelli, Barbaranelli, \& Caprara, 1999; Byrne, 2000; Greenberg et al., 1992; Seals \& Young, 2003; Wilburn \& Smith, 2005). Adolescents who stutter and adolescents who do not stutter with higher levels of anxiety also scored more poorly/lower on the general selfesteem scale. Poor self-esteem may contribute to higher levels of anxiety or higher levels of chronic anxiety may contribute to feelings of lower self-esteem. It would be interesting to determine the directionality of the relationship in adolescents who stutter. Do these participants develop poor self-esteem from teasing, bullying, peer rejection, low selfconcepts and then display higher levels of anxiety? It may be possible that some adolescents who stutter are physiologically susceptible or temperamentally suited (Anderson, Pellowski, Conture, \& Kelly, 2003; Buss \& Plomin, 1984; Guitar, 2003; Lewis $\&$ Goldberg, 1997) to display higher levels of anxiety which may result in lower selfesteem.

Similar to other studies reporting on anxiety and co-occurring disorders in adolescents with disabilities (Axelson \& Birmaher, 2001; Brady \& Kendall, 1992; Breslau, 1985; Sears \& Armstrong, 1998; Williams et al., 2003), there appears to be a relationship between cooccurring disorders (both non-speech language and speech-language) and anxiety. Adolescents who stutter with anxiety scores at least one standard deviation above the mean also exhibited the highest number of other co-occurring disorders. Due to the preliminary nature of these results, studies with larger samples, multiple anxiety measures and participants who have received treatment and those who have not received treatment for either their anxiety or fluency disorders appear warranted.

Research clearly shows that children with anxiety disorders are at higher risk for depression and other related emotional disorders and need to be monitored (Bandura et al., 1999; Byrne, 2000; Wilburn \& Smith, 2005). Although speculative in nature, it is possible that students who stutter with multiple co-occurring disorders may also be at a higher risk for increased anxiety levels and diagnosed anxiety disorders. Further research needs to address this issue in a systematic manner. For clinicians, the issue of prioritizing treatment for co-occurring disorders becomes paramount for adolescents who stutter. The presence of co-occurring disorders including heightened levels of anxiety reinforces the critical need for SLPs, parents, educational personnel and adolescents to work as a team in developing appropriate and successful treatment interventions for this age group.

We did not find any significant relationships between anxiety and stuttering severity. We predicted that as stuttering severity increased, the visibility of the disorder and potential for negative reactions of listeners and conversation partners might heighten levels of anxiety. Although this was not the case in the present sample, the preliminary nature of these findings and the impact of treatment could account for these results.

Additional studies employing a pre-screening for general or specific anxiety disorders could examine the overall effects on treatment and psychosocial development/adjustment. 
Adolescents who display anxiety specific to their stuttering disorder could also be examined for the effectiveness of specific treatments as well as the benefits of team approaches (multiple health and school personnel). The question of whether the anxiety predates, develops on a parallel course, or actually increases with stuttering needs to be investigated in children and adolescents through longitudinal investigations. The temporal relationship may be important for determining treatment regimes or even assist in preventing stuttering from becoming a chronic disorder in some children. Recently, Alm and Risberg (in press) reported on the relationship among stuttering, biochemical variables, temperament, heredity, pre-onset lesions, neuromuscular activity, and anxiety in 32 adults who stutter and 32 adults who do not stutter. They proposed a possible interpretation of their data that some cases of stuttering may be caused by neurological incidents, often resulting in co-occurring disorders and a tendency towards increased anxiety. Comparative studies using multiple self-report, hormonal anxiety measures, neuromuscular and physiological markers, larger samples, and adolescents from diverse backgrounds could be conducted to increase our understanding of the complexities of the stuttering-anxiety relationship in children and adolescents.

\section{Appendix A. Continuing education}

1. According to this study, which of the following statements is (are) correct/true?

a. physiological and emotional anxiety has been reported in persons who stutter.

b. one study reported that as high as $44 \%$ of clients seeking treatment for stuttering could be assigned a co-occurring social phobia or social anxiety diagnosis.

c. researchers question the results of anxiety studies with PWS due to methodical issues.

d. only a and $b$.

e. all of the above are correct/true.

Answer: E.

2. When discussing/reviewing anxiety in children and adolescents:

a. researchers suggest that the prevalence of anxiety disorders in children and adolescents may be as high as $20 \%$.

b. researchers suggest that children and youth with anxiety disorders may be at higher risk for educational underachievement, depression, poorer social support networks and increased family conflicts.

c. adolescents with disabilities may be at higher risk for anxiety and anxiety related disorders.

d. anxiety disorders have also been reported as more common in children with communication disorders.

e. all of the above are true statements according to the literature review.

Answer: E

3. Which of the following statements is (are) true according to this study?

a. high levels of anxiety can negatively affect the lives of children and adolescents.

b. adolescents who stutter with co-occurring disorders displayed significantly higher levels of anxiety than adolescents who stutter with no co-occurring disorders. 
c. no significant differences were found between groups on ethnicity, socioeconomic class, gender and anxiety levels.

d. a positive, significant correlation between anxiety scores and self-esteem scores was found for both groups.

e. all of the above.

Answer: E.

4. According to the results presented in this study adolescents who stutter:

a. displayed group mean T-scores for the Revised Children's Manifest Anxiety Scale outside the normative range for adolescents.

b. displayed group mean T-scores for the Revised Children's Manifest Anxiety Scale within the normative range for adolescents.

c. displayed group mean T-scores for the Revised Children's Manifest Anxiety Scale significantly different when compared to adolescents who do not stutter.

d. both a and $c$.

e. both $b$ and $c$.

Answer: E.

5. According to the discussion presented in this study:

a. unlike other studies reporting on anxiety and co-occurring disorders in adolescents with disabilities, these results do not support a relationship between co-occurring disorders (both non-speech language and speech-language) and anxiety.

b. the results of this study show a strong positive relationship between anxiety and stuttering severity.

c. the results of this study show a strong positive relationship between self-esteem and levels of anxiety for both adolescents who stutter and adolescents who do not stutter.

d. both $a$ and $b$.

e. none of the above are included in the discussion of this study.

Answer: C.

\section{References}

Alm, P. A., \& Risberg, J. (in press). Stuttering in adults: The acoustic startle response, temperamental traits, and biological factors. Journal of Communication Disorders.

Ameringen, M., Mancini, C., \& Farvolden, P. (2003). The impact of anxiety disorders on educational achievement. Journal of Anxiety Disorders, 17(5), 561-571.

Anderson, J., Pellowski, M., Conture, E., \& Kelly, E. (2003). Temperamental characteristics of young children who stutter. Journal of Speech, Language, and Hearing Research, 46(5), 1221.

Axelson, D. A., \& Birmaher, B. (2001). Relation between anxiety and depressive disorders in childhood and adolescence. Depression and Anxiety, 14, 67-78.

Balon, R. (2004). Developments in treatment of anxiety disorders: Psychotherapy, pharmacotherapy, and psychosurgery. Depression and Anxiety, 19, 63-76.

Bandura, A., Pastorelli, C., Barbarnelli, C., \& Caprara, G. (1999). Self-efficacy pathways to childhood depression. Journal of Personality and Social Psychology, 76(2), 258-269.

Bebout, L., \& Bradford, A. (1992). Cross-cultural attitudes toward speech disorders. Journal of Speech and Hearing Research, 35(1), 45-52.

Beitchman, J., Wilson, B., Johnson, C., Atkinson, L., Young, A., Adlar, E., et al. (2001). Fourteen-year follow-up of speech/language impaired and control children: Psychiatric outcome. Journal of American Academy of Child and Adolescent Psychiatry, 40, 75-82. 
Blomgren, M., Roy, N., Callister, T., \& Merrill, R. (2005). Intensive stuttering modification therapy: A multidimensional assessment of treatment outcomes. Journal of Speech, Language, and Hearing Research, 48(3), 509-523.

Blood, G. (1995). A behavioral-cognitive therapy program for adults who stutter: Computers and counselling. Journal of Communication Disorders, 28(2), 165-180.

Blood, G. (1998). Differential diagnosis for fluency disorders. In B. J. Philips, \& D. M. Ruscello (Eds.), Differential diagnosis in speech language pathology (pp. 159-188). Boston: Butterworth-Heinemann.

Blood, G., Blood, I., Bennett, T., Simpson, K., \& Susman, E. (1994). Subjective anxiety measurements and cortisol responses in adults who stutter. Journal of Speech and Hearing Research, 37, 561-570.

Blood, G., Blood, I., Tellis, G., \& Gabel, R. (2003). A preliminary study of self-esteem, stigma, and disclosure in adolescents who stutter. Journal of Fluency Disorders, 28, 143-159.

Blood, G., Wertz, H., Blood, I., Bennett, T., \& Simpson, K. (1997). The effects of life stressors and daily stressors on stuttering. Journal of Speech, Language, and Hearing Research, 40, 134-143.

Bloodstein, O. (1995). A handbook on stuttering (5th ed.). San Diego, CA: Singular Publishing Group Inc.

Brady, E. U., \& Kendall, P. C. (1992). Comorbidity of anxiety and depression in children and adolescents. Psychological Bulletin, 111(2), 244-255.

Breslau, N. (1985). Psychiatric disorder in children with physical disability. Journal of American Academy of Child Psychiatry, 24, 87-94.

Buss, A., \& Plomin, R. (1984). Temperament: Early developing personality traits.. Hillsdale, NJ: Erlbaum.

Byrne, B. (2000). Relationships between anxiety, fear, self-esteem, and coping strategies in adolescence. Journal of Adolescence, 35(137), 201-215.

Cantwell, D., \& Baker, L. (1987). The prevalence of anxiety in children with communication disorders. Journal of Anxiety Disorders, 1(3), 239-248.

Cantwell, D., \& Baker, L. (1988). Anxiety disorders in children with communication disorders: Correlates and outcome. Journal of Anxiety Disorders, 2(2), 135-146.

Caruso, A. J., Chodzko-Zajko, W. J., Bidinger, D. A., \& Sommers, R. K. (1994). Adults who stutter: Responses to cognitive stress. Journal of Speech and Hearing Research, 37, 746-754.

Cohen, J. (1988). Statistical power analysis for the behavioral sciences (2nd ed.). Hillsdale, NJ: Lawrence Earlbaum Associates.

Corcoran, J. A., \& Stewart, M. (1998). Stories of stuttering: A qualitative analysis of interview narratives. Journal of Fluency Disorders, 23, 247-264.

Costello, E. J., \& Angold, A. (1995). Epidemiology. In J. S. March (Ed.), Anxiety disorders in children and adolescents (pp. 109-124). New York: Guilford.

Craig, A. (1990). An investigation into the relationship between anxiety and stuttering. Journal of Speech and Hearing Disorders, 55, 290-294.

Craig, A. (1994). Anxiety levels in persons who stutter: Comments on the research of Miller and Watson (1992). Journal of Speech and Hearing Research, 37, 90-92.

Craig, A., \& Hancock, K. (1996). Anxiety in children and young adolescents who stutter. Australian Journal of Human Communication Disorders, 24, 28-38.

Craig, A., Hancock, K., Tran, Y., \& Craig, M. (2003). Anxiety levels in PWS: A randomized population study. Journal of Speech, Language, and Hearing Research, 46, 1197-1206.

Crichton-Smith, I. (2002). Communicating in the real world: Accounts from people who stammer. Journal of Fluency Disorders, 27, 333-352.

Crowe, T. A., \& Walton, J. H. (1981). Teacher attitudes toward stuttering. Journal of Fluency Disorders, 6, $163-$ 174.

DeCarle, A. J., \& Pato, M. T. (1996). Social phobia and stuttering. The American Journal of Psychiatry, 153, 1367-1368.

Dietrich, S., \& Roaan, M. (2001). Physiologic arousal and predictions of anxiety by people who stutter. Journal of Fluency Disorders, 26, 207-225.

Ezrati-Vinacour, R., \& Levin, I. (2004). The relationship between anxiety and stuttering: A multidimensional approach. Journal of Fluency Disorders, 29, 135-148.

Fitzgerald, H. E., Djurdjic, S. D., \& Maguin, E. (1992). Assessment of sensitivity to interpersonal stress in stutterers. Journal of Fluency Disorders, 25, 31-42. 
Gabel, R., Colcord, R., \& Petrosino, L. (2002). Self-reported anxiety of adults who do and do not stutter. Perceptual and Motor Skills, 94, 775-784.

Greenberg, J., Solomon, S., Pyszczynski, T., Rosenblatt, A., Burling, J., Lyon, D., et al. (1992). Why do people need self-esteem? Converging evidence that self-esteem serves an anxiety-buffering function. Journal of Personality and Social Psychology, 63(6), 913-922.

Guitar, B. (2003). Acoustic startle responses and temperament in individuals who stutter. Journal of Speech, Language, and Hearing Research, 46, 233-240.

Guitar, B. (2005). Stuttering: An integrated approach to its nature and treatment. Baltimore, MD: Williams \& Wilkins.

Hagborg, W. J. (1996). Scores of middle-school-age students on the Rosenberg Self-esteem Scale. Psychological Reports, 78(3), 1071-1074.

Ham, R. E. (1990). What is stuttering: Variations and stereotypes. Journal of Fluency Disorders, 15(5/6), 259-273 (Abstract).

Hancock, K., \& Craig, A. (1998). Predictors of stuttering relapse one year following treatment for children aged 9 to 14 years. Journal of Fluency Disorders, 23, 31-48.

Hancock, K., Craig, A., Campbell, K., Costello, D., Gilmore, G., McCaul, A., et al. (1998). Two to six year controlled trial stuttering outcomes for children and adolescents. Journal of Speech, Language, and Hearing Research, 41, 1242-1252.

Hoge, D. R., \& McCarthy, J. D. (1983). Issues of validity and reliability in the use of realdeal discrepancy scores to measure self-regard. Journal of Personality and Social Psychology, 44(5), 1048-1055.

Hollingshead, A. B. (1975). Four factor index of social status. Unpublished manuscript. New Haven, CT: Yale University.

Hollingshead, A. B., \& Redlich, F. C. (1958). Social class and mental illness: A community study. New York: Wiley.

Hommel, K. A., Chaney, J. M., Wagner, J. L., White, M. M., Hoff, A. L., \& Mullins, L. L. (2003). Anxiety and depression in older adolescents with long-standing asthma: The role of illness uncertainty. Children's Health Care, 32(1), 51-63.

Jackson, K., Ciechomski, L., King, N. J., Tonge, B., \& Heyne, D. (2002). Creating confident children: A groupbased parent-skills training program.

King, N. J., Heyne, D., \& Ollendick, T. H. (2005). Cognitive-behavioral treatments for anxiety and phobic disorders in children and adolescents: A review. Behavioral Disorders, 30(3), 241-257.

King, N. J., Ollendick, T. H., Gullone, E., Cummins, R., \& Josephs, A. (1990). Fears and phobias in children and adolescents with intellectual disabilities. Assessment and intervention strategies. Australia and New Zealand Journal of Developmental Disabilities, 16, 97-108.

Klompas, M., \& Ross, E. (2004). Life experiences of people who stutter, and the perceived impact of stuttering on quality of life: Personal accounts of South African individuals. Journal of Fluency Disorders, 29, 275305.

Kraaimaat, F. W., Jansseen, P., \& Brutten, G. J. (1988). The relationship between stutterers' cognitive and autonomic anxiety and therapy outcome. Journal of Fluency Disorders, 13, 107-113.

Kraaimaat, F. W., Vanryckeghem, M., \& Van Dam-Baggen, R. (2002). Stuttering and social anxiety. Journal of Fluency Disorders, 27, 319-331.

Lewis, K., \& Goldberg, L. (1997). Measurements of temperament in the identification of children who stutter. European Journal of Disorders of Communication, 32, 441-448.

Lorr, M., \& Wunderlich, R. A. (1986). Two objective measures of self-esteem. Journal of Personality Assessment, 50(10), 18-23.

Mahr, G. C., \& Torosian, T. (1999). Anxiety and social phobia in stuttering. Journal of Fluency Disorders, 24, 199 126.

Manassis, K., Avery, D., Butalia, S., \& Mendlowitz, S. (2004). Cognitive-behavioral therapy with childhood anxiety disorders: Functioning in adolescence. Depression and Anxiety, 19, 209-216.

Manning, W. H. (2001). Clinical decision making in the diagnosis and treatment of stuttering disorders (2nd ed.). Vancouver, Canada: Singular Thompson Learning.

Menzies, R., Onslow, M., \& Packman, A. (1999). Anxiety and stuttering: Exploring a complex relationship. American Journal of Speech-Language Pathology, 8, 3-10. 
Messenger, M., Onslow, M., Packman, A., \& Menzies, R. (2004). Social anxiety in stuttering: Measuring negative social expectancies. Journal of Fluency Disorders, 29, 201-212.

Miller, S., \& Watson, B. C. (1992). The relationship between communication attitude, anxiety, and depression in stutterers and nonstutterers. Journal of Speech and Hearing Research, 35, 789-798.

Pine, D. S., Cohen, P., Gurley, D., Brook, J., \& Ma, Y. (1998). The risk for early-adulthood anxiety and depressive disorders in adolescents with anxiety and depressive disorders. Archives of General Psychiatry, 55, 56-64.

Reader, M. J., Harris, E. L., Schuerholz, L. I., \& Denckla, M. B. (1994). Attention deficit hyperactivity disorder and executive dysfunction. Developmental Neuropsychology, 10, 493-512.

Reynolds, C. R., \& Richmond, B. O. (2002). Revised Children's Manifest Anxiety Scale (RCMAS). Los Angeles, CA: Western Psychological Services.

Riley, G. (1994). Stuttering severity instrument for children and adults (3rd ed.). Austin, TX: Pro-Ed.

Rosenberg, M. (1965). Society and the adolescent self-image. Princeton, NJ: Princeton University Press.

Rosenberg, M. (1979). Conceiving the self. New York: Basic Books.

Rosenberg, M. (1986). Conceiving the self. Malabar, FL: Krieger.

Ruscello, D. M., Lass, N. J., Schmitt, J. F., \& Pannbacker, M. D. (1994). Special educators' perceptions of stutterers. Journal of Fluency Disorders, 19(2), 125-132.

Schneier, F., Wexler, K., \& Liebewitz, M. (1997). Social phobia and stuttering. American Journal of Psychiatry, 154(1), 131 .

Seals, D., \& Young, J. (2003). Bullying and victimization: Prevalence and relationship to gender, grade level, ethnicity, self-esteem, and depression. Journal of Adolescence, 38(152), 735.

Sears, H. A., \& Armstrong, V. H. (1998). A prospective study of adolescents' self-reported depressive symptoms: Are risk behaviours a stronger predictor than anxiety symptoms? Canadian Journal of Behavioural Science, 30(4), 225-233.

Seligman, L. D., Ollendick, T. H., Langley, A. K., \& Balducci, H. B. (2004). The utility of measures of child and adolescent anxiety: A meta-analytic review of the Revised Children's Manifest Anxiety Scale, the State-Trait Anxiety Inventory for Children, and the Child Behavior Checklist. Journal of Clinical Child and Adolescent Psychology, 33(3), 557-565.

Shapiro, D. A. (1999). Stuttering intervention. Austin, TX: Pro-Ed.

Silverman, F. H. (2004). Stuttering and other fluency disorders (3rd ed.). Long Grove, IL: Waveland Press Inc.

Stein, M., Baird, A., \& Walker, J. (1996). Social phobia in adults with stuttering. American Journal of Psychiatry, $153,278-280$.

Turnbaugh, K. R., Guitar, B. E., \& Hoffman, P. R. (1979). Speech clinicians' attribution of personality traits as a function of stuttering severity. Journal of Speech and Hearing Disorders, 22, 37-45.

Van Riper, C. (1982). The treatment of stuttering. Englewood Cliffs, NJ: Prentice-Hall.

Velting, O. N., Setzer, N. J., \& Albano, A. M. (2004). Update on and advances in assessment and cognitivebehavioral treatment of anxiety disorders in children and adolescents. Professional Psychology: Research and Practice, 35(1), 42-54.

Voci, S. C., Beitchman, J. H., Brownlie, E. B., \& Wilson, B. (2006). Social anxiety in late adolescence: The importance of early childhood language impairment. Journal of Anxiety Disorders, 20, 915-930.

Weber, C. M., \& Smith, A. (1990). Autonomic correlates of stuttering and speech assessed in a range of experimental tasks. Journal of Speech and Hearing Research, 33, 690-706.

White, K. S., \& Farrell, A. D. (2001). Structure of anxiety symptoms in urban children: Competing factor models of the Revised Children's Manifest Anxiety Scale. Journal of Consulting and Clinical Psychology, 69, 333339.

Wilburn, V., \& Smith, D. (2005). Stress, self-esteem, and suicidal ideation in late adolescents. Journal of Adolescence, 40(157), 33-46.

Williams, J., Steel, C., Sharp, G. B., Delos Reyes, E., Phillips, T., Bates, S., et al. (2003). Anxiety in children with epilepsy. Epilepsy and Behavior, 4, 729-732.

Woods, C. L., \& Williams, D. E. (1971). Speech clinicians' conceptions of boys and men who stutter. Journal of Speech and Hearing Disorders, 36, 225-234.

Yovetich, W. S., Leschied, A. W., \& Flicht, J. (2000). Self-esteem of school-age children who stutter. Journal of Fluency Disorders, 25, 143-153. 